\title{
Meiosis of triploid Lolium. II. Discrepancies between the analyses of chromosome configurations at metaphase $I$ in inverse autoallotriploid combinations
}

\author{
HUW M. THOMAS \\ Institute of Grassland and Environmental Research, Plas Gogerddan, Aberystwyth, SY23 3EB, Wales, U.K.
}

\begin{abstract}
Chromosome configurations were analysed at metaphase I in six plants of each of the two inverse autoallotriploid types of Lolium temulentum $\times L$. multiflorum with the genome combinations TTM and TMM. In the combination with two large genomes and one small (TTM), there was no preferential pairing but with two small genomes and one large (TMM) there was preferential pairing. The findings are discussed in relation to the differences in DNA amounts of the two species and the associated differences in meiotic times of larger and smaller genomes. The results question the value of pairing data in triploids for the assessment of the relatedness of diploid species.
\end{abstract}

Keywords: autoallotriploid, genotype, Lolium, nucleotype, preferential pairing.

\section{Introduction}

Differences in DNA amounts among Festuca species have profound effects on chromosome pairing in the diploid hybrids based on analyses at metaphase I (Morgan et al., 1986). Although Lolium temulentum has 50 per cent more DNA than L. multiflorum (Hutchinson et al., 1979), the chromosomes pair as seven bivalents in the diploid hybrid, and in some cases show little, if any, preferential pairing in the autoallotriploid with two sets of $L$. temulentum chromosomes and one of L. multiflorum (Evans \& Aung, 1985).

Analysesofchromosomeconfigurationsatmetaphase I are considered valid in studying the phylogenetic relationships of parental species in interspecific hybrids. The fundamental assumption of such analyses is that homologous or closely related chromosomes will be held together by chiasmata at metaphase I and the frequency of such associations is taken as a measure of the degree of homology between the chromosomes and hence the relatedness of the species.

Diploid $L$. temulentum and $L$. multiflonum of the same accessions as used in the present study have seven ring bivalents at metaphase I and the auto-

${ }^{*}$ Correspondence. triploids have mean trivalent frequencies of between 5.70 and 6.22 per cell (Thomas, 1994). A comparison of trivalent numbers recorded at pachytene and metaphase I in aneuploid autotriploid $L$. multiflorum shows that 88 per cent of trivalents are maintained. This is consistent with that expected from the number of pairing partner exchanges at pachytene and chiasmata at metaphase I, that is, there is no elimination of multivalents in this accession of $L$. multiflorum (Thomas \& Thomas, 1994).

To examine the nature of the effect of quantitative DNA differences on chromosome pairing in Lolium, metaphase I configurations were analysed in the two inverse autoallotriploids between $L$. multiflorum (M) and L. temulentum (T), that is, with the genomic constitutions, TTM and TMM.

\section{Materials and methods}

The two diploid accessions used were $L$. multiflorum ssp. westerwoldicum $\mathrm{Bb} 2074$ and $L$. temulentum Ba3081. Diploid and synthetic autotetraploid cytotypes of these accessions were used to produce the autoallotriploids. Diploid or tetraploid L. temulentum was emasculated and pollinated by the contrasting cytotype of $L$. multiflorum. Immature embryos were removed 18 days after pollination and cultured on a modified Gamborg B5 medium (Gamborg et 
al., 1968) with 3 per cent sucrose but without 2,4D and kinetin.

For meiotic analyses at metaphase I, inflorescences were fixed in 6:3:1 Carnoy's solution and anthers squashed in 1 per cent aceto-carmine with gentle heating. Some anthers were stained in alcoholic hydrochloric acid carmine (Snow, 1963) and squashed in 45 per cent acetic acid.

\section{Results}

The parameters of paired chromosomes at metaphase I were recorded in 18-20 PMCs in each of six plants from the two types of autoallotriploid and the means are presented in Table 1 . A joint regression analysis shows that the effect of chiasmata on trivalent frequency is highly significant in both TTM and TMM types $(P<0.001)$. A parallel curve analysis shows that the constants (intercepts) are highly significantly different $(P<0.001)$ and the effect of chiasmata is significantly different $(P<0.05)$, that is, the slopes are different. It follows that trisomes with the same number of chiasmata are less likely to be associated as trivalents in TMM than TTM autoallotriploids. This was confirmed by a series of analyses of variance of trivalents per cell in cells with the same chiasma number in the two types of autoallotriploid (Table 2).

An analysis of variance of trivalents with chiasmata as covariate shows that both the covariate and type (TTM and TMM) have highly significant effects on trivalent numbers (Table 3). When the effect of chiasmata is removed, there is still more than twice the number of trivalents per cell in TTM than TMM (Table 1).

With the large difference in the number of trivalents between TTM and TMM, there is a commensurate and inverse difference in bivalents and univalents. However, it is not only the total number of bivalents that is different between types. The ratio of rods to rings in TTM is 1:4.7 but in TMM it is $1: 40.3$. A contingency $\chi^{2}$ on the totals confirmed the difference to be highly significant $\left(\chi_{1}^{2}=63.27\right.$; $P<0.001)$.

In most cells of TMM plants, the difference in size of the chromosomes was obvious, though this did seem more pronounced in some plants than others. The bivalents were between the smaller chromosomes, that is, homologous pairs of $L$. multiflorum chromosomes. No heteromorphic bivalents were recorded. One rod bivalent in TMM plant 4 was between two chromosomes of $L$. temulentum and three examples were found in other TMM plants of rod associations between $L$. temulentum chromosomes that were judged to be achiasmate. Although the difference in the size of the chromosomes of the two species appeared less marked in the TTM combination, bivalents between homoeologous chromosomes probably would have been detected, but none was found.

Table 1 Plant means of chromosome configurations at metaphase I in two inverse types of autoallotriploid Lolium: L. temulentum $(4 \mathrm{x}) \times$ L. multiflorum $(2 \mathrm{x})=\mathrm{TTM}$, L. temulentum $(2 \mathrm{x}) \times L$. multiflorum $(4 \mathrm{x})=\mathrm{TMM}$

\begin{tabular}{|c|c|c|c|c|c|c|c|c|c|c|c|c|c|}
\hline \multirow{2}{*}{$\begin{array}{l}\text { Triploid } \\
\text { type }\end{array}$} & \multirow{2}{*}{$\begin{array}{c}\text { Plant } \\
\text { no. }\end{array}$} & \multirow{2}{*}{$\begin{array}{l}\text { No. of } \\
\text { cells }\end{array}$} & \multirow[b]{2}{*}{ I } & \multicolumn{3}{|c|}{ II } & \multicolumn{5}{|c|}{$\mathrm{III} \dagger$} & \multirow[b]{2}{*}{ Chiasmata } & \multirow[b]{2}{*}{ III $^{*}$} \\
\hline & & & & Rod & Ring & Total & $\mathrm{Ch}$ & $\operatorname{Tr}$ & $\mathrm{Fp}$ & $\mathrm{Bc}$ & Total & & \\
\hline \multirow[t]{6}{*}{ TTM } & 1 & 20 & 1.90 & 0.35 & 1.55 & 1.90 & 1.85 & 0.30 & 2.90 & 0.05 & 5.10 & 19.00 & 4.87 \\
\hline & 2 & 18 & 1.78 & 0.11 & 1.67 & 1.78 & 2.17 & 0.22 & 2.61 & 0.22 & 5.22 & 18.28 & 5.17 \\
\hline & 3 & 20 & 1.60 & 0.20 & 1.40 & 1.60 & 1.55 & 0.50 & 2.85 & 0.50 & 5.40 & 21.20 & 4.64 \\
\hline & 4 & 18 & 1.65 & 0.25 & 1.40 & 1.65 & 1.44 & 0.50 & 2.67 & 0.33 & 5.17 & 19.44 & 4.83 \\
\hline & 5 & 20 & 1.95 & 0.75 & 1.20 & 1.95 & 2.20 & 0.70 & 2.10 & 0.05 & 5.05 & 16.45 & 5.44 \\
\hline & 6 & 20 & 1.25 & 0.10 & 1.15 & 1.25 & 2.40 & 0.05 & 3.20 & 0.10 & 5.70 & 19.05 & 5.46 \\
\hline Means & & 116 & 1.72 & 0.30 & 1.41 & 1.72 & 1.94 & 0.40 & 2.72 & 0.21 & 5.27 & 18.90 & 5.07 \\
\hline \multirow[t]{6}{*}{ TMM } & 1 & 20 & 5.90 & 0.05 & 5.75 & 5.80 & 0.30 & 0.05 & 0.80 & 0.00 & 1.15 & 15.75 & 1.71 \\
\hline & 2 & 20 & 4.70 & 0.15 & 4.55 & 4.70 & 1.10 & 0.10 & 1.15 & 0.00 & 2.30 & 18.10 & 2.29 \\
\hline & 3 & 20 & 4.90 & 0.10 & 4.70 & 4.80 & 0.80 & 0.00 & 1.30 & 0.00 & 2.15 & 15.80 & 2.70 \\
\hline & 4 & 20 & 5.10 & 0.25 & 5.15 & 5.40 & 0.75 & 0.00 & 0.90 & 0.00 & 1.70 & 15.70 & 2.27 \\
\hline & 5 & 20 & 4.15 & 0.05 & 4.10 & 4.15 & 0.75 & 0.10 & 2.10 & 0.00 & 2.85 & 18.70 & 2.70 \\
\hline & 6 & 20 & 4.80 & 0.00 & 4.80 & 4.80 & 0.60 & 0.05 & 1.55 & 0.00 & 2.20 & 19.25 & 1.91 \\
\hline Means & & 120 & 4.93 & 0.12 & 4.84 & 4.94 & 0.72 & 0.05 & 1.30 & 0.00 & 2.06 & 17.22 & 2.26 \\
\hline
\end{tabular}

III $\dagger$ types: $\mathrm{Ch}=$ chain, $\mathrm{Tr}=$ triradial, $\mathrm{Fp}=$ frying pan, $\mathrm{Bc}=$ bird cage.

III* Trivalents adjusted for chiasmata as covariate in the analysis of the 12 plants.

(c) The Genetical Society of Great Britain, Heredity, 75, 446-452. 
Table 2 Analyses of variance of trivalents per chiasma class for both autoallotriploid types (TTM and TMM) of Lolium

\begin{tabular}{lccccc}
\hline & \multicolumn{4}{c}{ Mean number of trivalents } & \\
\cline { 2 - 5 } Chiasmata & TTM & $(N)^{*}$ & TMM & $(N)$ & Significance \\
\hline 15 & 3.80 & 5 & 1.52 & 21 & $P<0.001$ \\
16 & 4.70 & 10 & 1.57 & 14 & $P<0.001$ \\
17 & 5.00 & 16 & 2.06 & 17 & $P<0.001$ \\
18 & 5.53 & 19 & 2.27 & 11 & $P<0.001$ \\
19 & 5.44 & 18 & 3.35 & 20 & $P<0.001$ \\
20 & 5.37 & 19 & 2.25 & 16 & $P<0.001$ \\
21 & 5.67 & 9 & 2.75 & 4 & $P<0.001$ \\
\hline
\end{tabular}

${ }^{*}$ Number of observations.

Table 3 Analysis of variance of trivalents adjusted for the covariate chiasmata for both autoallotriploid types (TTM and TMM) of Lolium

\begin{tabular}{lcrrrc}
\hline $\begin{array}{l}\text { Source of } \\
\text { variation }\end{array}$ & $\begin{array}{c}\text { Degrees of } \\
\text { freedom }\end{array}$ & $\begin{array}{c}\text { Sums of } \\
\text { squares }\end{array}$ & $\begin{array}{c}\text { Mean } \\
\text { squares }\end{array}$ & $\begin{array}{c}\text { Variance } \\
\text { ratios }\end{array}$ & Significance \\
\hline Between types & 1 & 433.506 & 433.506 & 288.25 & $P<0.001$ \\
Between plants & 10 & 26.569 & 2.657 & 1.77 & NS \\
Covariate & 1 & 47.237 & 47.237 & 31.41 & $P<0.001$ \\
Residual & 223 & 335.374 & 1.504 & & \\
Total & 235 & 1032.386 & & & \\
\hline
\end{tabular}

\section{Comparisons of the autoallotriploids and autotrip/oids of $\mathrm{L}$. multiflorum and $\mathrm{L}$. temulentum}

The mean number of chiasmata and trivalents for autotriploid $L$. multiflorum and $L$. temulentum (Thomas, 1994) and the two autoallotriploids are presented for comparison in Table 4a. In each case, the means for the autoallotriploids are lower than those for the autotriploids $(P<0.001)$. Covariate analyses of variance showed the differences for trivalents to be at least partly dependent on chiasma frequency (Table 4b). These analyses show that the TMM autoallotriploids have significantly fewer trivalents than either autotriploid type in addition to the chiasma effect, but the TTM autoallotriploids do not differ from the autotriploids in this respect. That is, in the TTM autoallotriploids, there is no evidence of preferential pairing between the chromosomes of $L$. temulentum but there is preferential pairing between the $L$. multiflorum chromosomes in the TMM autoallotriploids.

The data were analysed by the method of Alonso $\&$ Kimber (1981) (Table 5). The terms $c$ and $x$, defined by Kimber et al. (1981) represent mean arm pairing frequency and relative affinity, respectively. The values of $c$ and $x$ and the expected frequencies of the meiotic chromosome configurations were calculated by the formulae given by Alonso \& Kimber (1981). In the TTM autoallotriploids the value of $x$ is between 0.549 and 0.626 indicating that these plants fit the 3:0 model. All of the TMM autoallotriploids have high values of $x$ and are 2:1 triploids.

\section{Distribution of trivalents}

PMCs were classed by number of trivalents and the distributions tested. The distribution in TTM fitted a positive binomial distribution $\left(\chi_{4}^{2}=0.86\right.$; NS) while the distribution of trivalents in TMM differed significantly from a positive binomial $\left(\chi_{4}^{2}=14.95\right.$; $P<0.01)$ but it fitted a negative binomial distribution $\left(\chi_{3}^{2}=2.79 ; \mathrm{NS}\right)$. This means that in TTM all trisomes have the same propensity to form trivalents, but in TMM some trisomes are more likely to form trivalents than others (cf. Hall, 1955). The mechanism that imposes preferential pairing between the $L$. multiflorum chromosomes in the TMM autoallotriploids is not equally expressed in all trisomes.

To test if chiasma frequency affects the distribution of trivalents, the populations of cells from both 
Table 4 Comparisons of chiasma and trivalent frequencies between the autotriploids and autoallotriploids of Lolium

a. Table of means

\begin{tabular}{lrrrr}
\hline & MMM & TTT & TTM & TMM \\
\hline Chiasmata & 21.38 & 22.11 & 18.90 & 17.22 \\
Trivalents & 5.90 & 6.22 & 5.27 & 2.06 \\
\hline
\end{tabular}

b. Summary of analyses of variance of trivalents adjusted for the covariate chiasmata

\begin{tabular}{lccc}
\hline & \multicolumn{2}{c}{ Adjusted means } & \\
\cline { 2 - 3 } Between types & Autotriploid & Allotriploid & Significance* \\
\hline MMM and TTM & 5.673 & 5.386 & NS \\
MMM and TMM & 5.307 & 2.355 & $P<0.001$ \\
TTT and TTM & 5.717 & 5.349 & NS \\
TTT and TMM & 4.990 & 2.240 & $P<0.001$ \\
\hline
\end{tabular}

*In each analysis the covariance effect is highly significant $(P<0.001)$.

the TTM and TMM types were divided into low chiasmata and high chiasmata groups for separate analysis. The PMCs of the TTM autoallotriploids were divided into groups with 13-18 chiasmata per cell in the low chiasmata group and PMCs with 19-24 chiasmata in the high group. This division gave groups of 53 and 63 cells, respectively. The distribution of trivalents in both TTM groups fitted the positive binomial distribution, with low $\chi^{2}$ values (low chiasmata group $\chi_{4}^{2}=1.44$; NS; high chiasmata group $\left.\chi_{3}^{2}=0.82 ; \mathrm{NS}\right)$. The TMM autoallotriploid PMCs were divided into groups with 12-17 chiasmata and 18-22 chiasmata with 66 and 54 PMCs per group, respectively. The low chiasmata group fitted the positive binomial with a low $\chi^{2}$ value $\left(\chi_{3}^{2}=0.04\right.$; NS). The high chiasmata group also did not differ significantly from the positive binomial but had a much larger $\chi^{2}$ value $\left(\chi_{3}^{2}=7.43\right.$; NS).

The size of the populations when PMCs are divided into high and low chiasmata types may be insufficient to test their distributions. The results do show, however, a very good fit to the positive binomial in both the TTM populations and also in the low chiasmata TMM. The larger $\chi^{2}$ in the high chiasma TMM PMCs, though not significant, indicates that it is in this category of PMCs that the nonuniform distribution of trivalents arises. Some trisomes in TMM may be more likely to form trivalents than others at prophase I but when the chiasma numbers are low, few of the trivalents are retained to metaphase I and the distribution does not show evidence of nonuniform trivalent formation. However, with high chiasma numbers there is a greater retention of trivalents and the pattern of pairing at prophase $I$ is more accurately reflected at metaphase I, resulting in a nonuniform formation of trivalents.

\section{Discussion}

The most striking feature of the analysis of metaphase I of the autoallotriploids is the very large difference in trivalent frequencies between the two inverse types. This is partly explained by differences in chiasma numbers, but the greater part of the difference remains unexplained. The comparisons of each autoallotriploid type with the autotriploids reveals that when the effect of chiasmata is excluded, the TTM autoallotriploids have the same capacity to form trivalents as the autotriploids. This means that there is no preferential pairing in the TTM combination. However, in the TMM autoallotriploids there is a strong indication of preferential pairing between the $L$. multiflorum chromosomes, excluding the $L$. temulentum chromosomes from most chiasmate associations.

Evans \& Aung (1985) identified a genotype of $L$. multiflorum which partly suppressed pairing between L. multiflorum and L. temulentum chromosomes and it was found to carry 'diploidizing genes'. However, this diploidizing genotype was isolated by analysing 1183 diploid hybrid plants from $30 \mathrm{~L}$. multiflorum 
Table 5 Observed and calculated meiotic analyses of autotriploid and autoallotriploid Lolium

\begin{tabular}{|c|c|c|c|c|c|c|c|c|c|}
\hline \multirow{2}{*}{$\begin{array}{l}\text { Triploid } \\
\text { type }\end{array}$} & \multirow{2}{*}{$\begin{array}{l}\text { Plant } \\
\text { no. }\end{array}$} & \multirow{2}{*}{$\begin{array}{l}\text { Source* } \\
\text { of data }\end{array}$} & \multirow[b]{2}{*}{ I } & \multicolumn{2}{|c|}{ II } & \multirow[b]{2}{*}{ III } & \multirow[b]{2}{*}{$c$} & \multirow[b]{2}{*}{$x$} & \multirow[b]{2}{*}{ SSD } \\
\hline & & & & Rods & Rings & & & & \\
\hline \multirow[t]{6}{*}{ MMM } & \multirow[t]{2}{*}{1} & Obs & 1.00 & 0.00 & 1.00 & 6.00 & \multirow[t]{2}{*}{1.000} & & \\
\hline & & Calc & 2.43 & 0.00 & 2.43 & 4.57 & & 0.600 & 6.1225 \\
\hline & \multirow[t]{2}{*}{2} & Obs & 1.00 & 0.05 & 0.95 & 6.00 & \multirow[t]{2}{*}{0.996} & & \\
\hline & & Calc & 2.47 & 0.05 & 2.42 & 4.53 & & 0.603 & 6.4526 \\
\hline & \multirow[t]{2}{*}{3} & Obs & 1.30 & 0.15 & 1.15 & 5.70 & \multirow[t]{2}{*}{0.989} & & \\
\hline & & Calc & 2.50 & 0.15 & 2.35 & 4.50 & & 0.588 & 4.3484 \\
\hline \multirow[t]{2}{*}{ TTT } & \multirow[t]{2}{*}{1} & Obs & 1.00 & 0.06 & 0.61 & 6.22 & \multirow[t]{2}{*}{0.980} & & \\
\hline & & Calc & 2.67 & 0.27 & 2.39 & 4.33 & & 0.625 & 9.5664 \\
\hline \multirow[t]{12}{*}{ TTM } & \multirow[t]{2}{*}{1} & Obs & 1.90 & 0.35 & 1.55 & 5.10 & \multirow[t]{2}{*}{0.975} & & \\
\hline & & Calc & 2.60 & 0.34 & 2.24 & 4.41 & & 0.554 & 2.7817 \\
\hline & \multirow[t]{2}{*}{2} & Obs & 1.78 & 0.11 & 1.67 & 5.22 & \multirow[t]{2}{*}{0.992} & & \\
\hline & & Calc & 2.43 & 0.11 & 2.32 & 4.57 & & 0.549 & 1.2636 \\
\hline & \multirow[t]{2}{*}{3} & Obs & 1.60 & 0.20 & 1.40 & 5.40 & \multirow[t]{2}{*}{0.986} & & \\
\hline & & Calc & 2.51 & 0.20 & 2.31 & 4.49 & & 0.549 & 2.4818 \\
\hline & \multirow[t]{2}{*}{4} & Obs & 1.65 & 0.25 & 1.40 & 5.17 & 0.956 & & \\
\hline & & Calc & 2.81 & 0.58 & 2.18 & 4.22 & & 0.576 & 2.9655 \\
\hline & 5 & Obs & 1.95 & 0.75 & 1.20 & 5.05 & 0.946 & & \\
\hline & & Calc & 2.91 & 0.71 & 2.14 & 4.13 & & 0.576 & 2.6427 \\
\hline & 6 & Obs & 1.25 & 0.10 & 1.15 & 5.70 & 0.986 & & \\
\hline & & Calc & 2.54 & 0.20 & 2.34 & 4.46 & & 0.590 & 4.6441 \\
\hline TMM & 1 & Obs & 5.90 & 0.05 & 5.75 & 1.15 & 0.989 & & \\
\hline & & Calc & 5.88 & 0.15 & 5.73 & 1.12 & & 0.954 & 0.0117 \\
\hline & 2 & Obs & 4.00 & 0.15 & 4.55 & 2.30 & 0.989 & & \\
\hline & & Calc & 4.47 & 0.15 & 4.32 & 2.53 & & 0.875 & 0.3277 \\
\hline & 3 & Obs & 4.90 & 0.10 & 4.70 & 2.15 & 0.986 & & \\
\hline & & Calc & 4.88 & 0.20 & 4.68 & 2.12 & & 0.901 & 0.0109 \\
\hline & 4 & Obs & 5.10 & 0.25 & 5.15 & 1.70 & 0.996 & & \\
\hline & & Calc & 5.20 & 0.05 & 5.15 & 1.80 & & 0.922 & 0.0601 \\
\hline & 5 & Obs & 4.15 & 0.05 & 4.10 & 2.85 & 0.996 & & \\
\hline & & Calc & 4.15 & 0.05 & 4.10 & 2.85 & & 0.855 & 0.0000 \\
\hline & 6 & Obs & 4.80 & 0.00 & 4.80 & 2.20 & 1.000 & & \\
\hline & & Calc & 4.80 & 0.00 & 4.80 & 2.20 & & 0.900 & 0.0000 \\
\hline
\end{tabular}

${ }^{*}$ Obs = Observed data from Thomas (1994) and Table 1. Calc $=$ Calculated from $x$ according to Alonso \& Kimber (1981). $c=$ mean arm-pairing frequency; $x=$ relative affinity; $\mathrm{SSD}=$ sum of squares of differences between observed and
calculated.

families. Clearly, such a genotype must be rare. It is extremely unlikely therefore that the six TMM plants analysed here all carried 'diploidizing genes' and some other explanation must be sought for the reduced trivalent frequency in TMM. In the TTM autoallotriploids there are two large genomes and one small: in the TMM autoallotriploids, there are two small genomes and one large. Could two small genomes in the presence of one large genome exert preferential pairing whereas two large genomes with one small genome fail to do so?
The occurrence of trivalents at metaphase I requires at least one pairing partner exchange (PPE) and at least two appropriately placed chiasmata. The difference in trivalent numbers between types is greater than that explained by different chiasma frequencies. It must therefore result from changed chiasma location or a reduction of PPEs or a change in PPE position.

A prophase I configuration with a single PPE in a median position and one chiasma would result in a rod bivalent and univalent, and with one or more 
chiasmata in each arm, in a chain trivalent. The low frequencies of rod bivalents and chain trivalents in TMM indicate that prophase I trivalents with one median PPE are rare. A high frequency of ring bivalents in TMM (most if not all of which are between homologues) demonstrates that both pairs of arms are synapsed homologously in the area of chiasma formation. The prophase I configuration would require no PPEs (that is, a bivalent and univalent at the outset) or an even number of PPEs located proximally to the sites of recombination so that the same two axial elements are paired in both subtelomeric SCs. With a chiasma in each of these SCs the prophase I trivalent would not be maintained to metaphase I but with a third chiasma formed in a more central position a frying pan trivalent could be formed with the $L$. temulentum chromosome forming the handle.

Synapsis is thought to begin in telomeric regions even in species with multiple pairing initiation sites (e.g. Hasenkampf, 1984). In TMM autoallotriploids, if the smaller chromosomes start pairing before the single large chromosome is ready to pair, then the telomeric regions of the pair of $L$. multiflorum chromosomes will be synapsed homologously. The final configuration at pachytene will be either a bivalent and univalent or a trivalent with a pair of approximately median PPEs with both of the distal SCs between homologous chromosomes. Only when a chiasma is formed in the homoeologous $\mathrm{SC}$ region will a trivalent be maintained to metaphase I. In TTM, if again the smaller chromosome is ready to synapse before the larger pair, then when the larger pair of chromosomes is ready to synapse, the smaller chromosome will be able to compete for all pairing initiation sites, including those near the telomere. In this case each chromosome has the same likelihood of synapsis in the subtelomeric regions, as was seen in the SC analysis of autotriploid L. multiflorum (Thomas \& Thomas, 1994).

Seal \& Rees (1982) and Seal (1983) examined the distribution of quantitative DNA changes in Lolium and Festuca diploid species. They found that an increase in DNA amount was achieved by similar amounts of DNA added to each chromosome. Consequently, in hybrids between species that differ in nuclear DNA amount, smaller homoeologues are structurally more dissimilar than the larger homoeologues. In a Festuca hybrid, smaller homoeologous pairs were found to be more likely to form abnormalities at pachytene than the larger pairs and less likely to form chiasmata.

In the TTM and TMM autoallotriploids studied here there is, based on the findings of Seal \& Rees
(1982), a greater disparity in chromosome size in the smaller trisomes than the larger trisomes. Examination of the cell to cell variation of trivalent numbers in the TTM autoallotriploids shows that all trisomes have the same probability of forming a trivalent as shown by the positive binomial distribution. In the TMM autoallotriploids the trivalent distribution fits a negative binomial indicating aggregation, that is, some trisomes are more likely to form trivalents than others. Based on the findings of Seal \& Rees (1982), Seal (1983) and Jenkins \& Rees (1983) it is tempting to speculate that it is in the smaller trisomes of TMM that the L. multiflorum pairs express the strongest preferential pairing.

The differences found between the two inverse types of autoallotriploid in this study have serious implications for the use of pairing data of synthetic polyploids in determining the phylogenetic relationships of the diploid species. It has been argued that the analysis of paired chromosomes at metaphase I in diploid hybrids is not a reliable measure of the relatedness of the genomes because chromosomes will pair with structurally diverse partners in the absence of a homologous partner - so called enforced pairing (Jauhar, 1988). In triploid hybrids between diploids and synthetic autotetraploids it is argued that chromosomes have a 'choice' of pairing partners. An analysis of data giving a 2:1 type (Kimber \& Yen, 1990) is taken to show a distant relationship between the diploid species whereas a 3:0 result demonstrates a close relationship between the species. Kimber \& Yen (1990) have devised 'numerical estimates of phylogenetic relationships' on the genome affinity calculated from metaphase I pairing data of autoallotriploids from autotetraploids $x$ diploids.

The mathematical analysis of the present data highlights the discrepancies between the TTM and TMM autoallotriploids. TTM is comparable with the autotriploids MMM and TTT indicating a very close relationship between the $M$ and $T$ genomes. However, TMM fits the 2:1 model indicating greater differentiation between the genomes. Wang (1992) considers that 'pairing data solely from triploid hybrids cannot be used to determine their basic genome symbols'. The above results support this statement, as quite different conclusions would have been arrived at depending on whether the autoallotriploid analysed had been the TTM or TMM type.

\section{References}

ALONSO, L. C. AND KIMBER, G. 1981. The analysis of meiosis in hybrids. II. Triploid hybrids. Can. J. Genet. Cytol., 23, 221-234. 
EVANS, G. M. AND AUNG, T. 1985. Identification of a diploidizing genotype of Lolium multiflorum. Can. J. Genet. Cytol., 27, 498-505.

GAMBORG, O. L., Miller, R. A. AND OJIMA, K. 1968. Nutrient requirements of suspension cultures of soyabean root cells. Exp. Cell Res., 50, 151-158.

HALL, B. M. 1955. Binomial analysis of chromosome behaviour in hybrid plants. Penn. Acad. Sci., 29, 121-126.

HASENKAMPF, C. A. 1984. Synaptonemal complex formation in pollen mother cells of Tradescantia. Chromosoma, 90, 275-284.

HUTCHINSON, J., REES, H. AND SEAL, A. G. 1979. An assay of activity of supplementary DNA in Lolium. Heredity, 43, 411-421.

JAUHAR, P. P. 1988. A reassessment of genome relationships between Thinopyrum bessarabicum and T. elongatum of the Triticeae. Genome, 30, 903-914.

JENKINS, G. AND REES, H. 1983. Synaptonemal complex formation in a Festuca hybrid. In: Brandham, P. E. and Bennett, M. D. (eds) Kew Chromosome Conference II, pp. 233-242. George Allen and Unwin, London.

KIMBER, G. AND YEN, Y. 1990. Genomic analysis of diploid plants. Proc. Natl. Acad. Sci. U.S.A., 87, 3205-3209.

KIMBER, G., ALONSO, L. C. AND SALlEE, P. J. 1981. Analysis of meiosis in hybrids. I. Aneuploid hybrids. Can. J.
Genet. Cytol., 23, 209-219.

MORGAN, W. G., THOMAS, H., EVANS, M. AND BORRILL, M. 1986. Cytogenetic studies of interspecific hybrids between diploid species of Festuca. Can. J. Genet. Cytol., 28, 921-925.

SEAL, A. G. 1983. The distribution and consequences of changes in nuclear DNA content. In: Brandham, P. E. and Bennett, M. D. (eds) Kew Chromosome Conference II, pp. 225-232. George Allen and Unwin, London.

SEAL, A. G., AND REES, H. 1982. The distribution of quantitative DNA changes associated with the evolution of diploid Festucae. Heredity, 49, 179-190.

sNow, R. 1963. Alcoholic hydrochloric acid-carmine as a stain for chromosomes in squash preparations. Stain Technol., 38, 9-13.

Thomas, н. м. 1994. An Analysis of Factors Affecting Chromosome Pairing in the Lolium-Festuca Complex Ph.D. Thesis, University of Wales.

THOMAS, H. M. AND THOMAS B. J. 1994. Meiosis in triploid Lolium. I. Synaptonemal complex formation and chromosome configurations at metaphase $I$ in aneuploid autotriploid L. multiflorum. Genome, 37, 181-189.

WANG, R. R.-C. 1992. Genome relationships in the perennial Triticeae based on diploid hybrids and beyond. Hereditas, 116, 133-136. 